\title{
SOMOS APRENDIZES DE ESCOLAS SUSTENTÁVEIS ${ }^{1}$
}

\author{
Rachel TRAJBER ${ }^{2}$ \\ Ministério da Educação \\ racheltrajber@mec.gov.br \\ Michèle SATO ${ }^{3}$ \\ Universidade Federal de Mato Grosso \\ michelesato@pq.cnpq.br \\ O horizontal pertence à natureza. \\ O vertical pertence ao humano.
}

(Hundertwasser)

Resumo: A educação ambiental cumpre papel importante quando se consideram processos de transformação socioambientais capazes de ressignificar tempos e espaços escolares. Ela favorece a participação de múltiplos atores no processo educativo e aponta outros percursos possiveis a serem trilhados pela escola e comunidade com a adoção de princípios e práticas sociais sustentáveis. Nesse sentido, Escolas Sustentáveis podem se tornar referências para suas comunidades, promovendo uma gestão mais democrática e participativa e reorganizando o currículo. É proposto um processo formativo a distância, implementado em escolas do ensino médio em um esforço que integra diversos setores do MEC.

Palavras-chave: Escolas Sustentáveis. Educação a Distância. Comunidade escolar.

Abstract: Environmental education fulfills an important role when considering socioenvironmental processes able to reframe concepts as time and space in schools. EE encourages the participation of multiple actors in the educational process and indicates other possible routes to be followed by school and community with the adoption of sustainable principles and new social practices. In this sense, Sustainable

\footnotetext{
${ }^{1}$ Este texto foi inicialmente publicado na Revista Pátio - Ensino Médio 5, Editora Artmed, 2010, com o título "Escolas que educam para a sustentabilidade" e sua publicação foi cedida pela editora.

${ }^{2}$ RACHEL TRAJBER é doutora em antropologia e coordenadora geral de educação ambiental do Ministério da Educação, MEC.

${ }^{3}$ MICHÈLE SATO é pós-doutora em educação e professora e pesquisadora em educação ambiental na Universidade Federal de Mato Grosso, UFMT. O texto contou com a colaboração de Tereza Moreira.
} 
Schools can become references for their communities by promoting a more democratic and participative management and reorganizing the curriculum. We propose a Distance Education process implemented in high schools in an effort that integrates the various sectors of the Ministry of Education.

Keywords: Sustainable Schools. Distance Education. School Community.

\section{Introdução}

\section{A Provocação}

A provocação partiu do Colóquio sobre Educação para a Sustentabilidade, do grupo de trabalho Matriz Energética para o Desenvolvimento com Equidade e Responsabilidade Socioambiental, do Conselho de Desenvolvimento Econômico e Social - CDES. O Relatório daquele conselho, aprovado em novembro de 2009, é enfático em seu chamamento:

"para que a educação ambiental seja efetiva e contribua para a mitigação dos efeitos das mudanças do clima e a formação de uma nova cidadania, foi consenso nas discussões entre os conselheiros que as instituições de ensino sejam incubadoras de mudanças concretas na realidade social, articulando três eixos: edificações, gestão e currículo".

Outra provocação vem do Plano Nacional sobre Mudança do Clima, que prevê a criação de espaços educadores sustentáveis nas escolas e universidades brasileiras para o urgente enfrentamento das mudanças socioambientais globais.

Espaços educadores sustentáveis são aqueles que têm a intencionalidade pedagógica de se constituir em referências concretas de sustentabilidade socioambiental. Isto é, são espaços que mantêm uma relação equilibrada com o meio ambiente; compensam seus impactos com o desenvolvimento de tecnologias apropriadas, permitindo assim, 
qualidade de vida para as gerações presentes e futuras.

Numa sociedade que se caracteriza pela circulação de tantas identidades e diversidades e, especialmente, no cenário dos espaços educadores sustentáveis, pensar a educação é pensá-la diferente. Hoje, o processo pedagógico requer uma reflexão ambiental para que a distância entre o pensar e o fazer também possa acolher o sentir no processo de criação. Uma educação integral ${ }^{4}$ deve incitar não apenas responsabilidades ecológicas, mas convidar para repensarmos nossas próprias vidas e o modelo de sociedade, cuidando do mundo por opção de quem acredita que a chamada educação ambiental não é mero pretexto à coleta seletiva de lixo, mas um convite à ressignificação de nossos modos de vida.

No contexto político da busca de sustentabilidade, apresentamos o Projeto Escolas Sustentáveis, ${ }^{5}$ que se configura como uma provocação para que as escolas de ensino médio reinventem a palavra, orientandose para novas trajetórias. Em outras palavras, o projeto é uma intervenção de políticas públicas, geradora de transformações face à emergência das mudanças socioambientais globais, e acata as orientações da Avaliação Ecossistêmica do Milênio e do Tratado de Educação Ambiental para Sociedades Sustentáveis e Responsabilidade Global, entre outros importantes documentos e movimentos ambientalistas locais, nacionais e mundiais.

A concepção do projeto reconhece a escola como um espaço educador sustentável em três dimensões conectadas: o espaço, o currículo e a gestão. O projeto incentiva que o espaço da escola seja repensado em articulação com o currículo, de acordo com as premissas da sustentabilidade socioambiental, gerando uma nova cultura na

${ }^{4}$ O Programa Mais Educação e a Educação Integral SECAD/MEC) tem por princípio a integração entre as políticas educacionais e sociais, em interlocução com as comunidades escolares e o incentivo à criação de espaços educadores sustentáveis com a readequação dos prédios escolares (incluindo a acessibilidade) à gestão, à formação de professores e à inserção das temáticas de sustentabilidade ambiental nos currículos e no desenvolvimento de materiais didáticos (Decreto 7.083/2010, inciso V, at. $2^{\circ}$ ).

${ }^{5}$ O Projeto nasceu pela ousadia da Coordenação Geral de Educação Ambiental do Ministério da Educação [MEC] em diálogos com três universidades federais de Ouro Preto [UFOP], de Mato Grosso do Sul [UFMS] e de Mato Grosso [UFMT]. 
comunidade escolar. Envolve estudantes, membros da comunidade, professores, funcionários e gestores em diálogos constantes voltados à melhoria da qualidade de vida, por meio da Comissão de Meio Ambiente e Qualidade de Vida (Com-Vida), uma ação estruturante da educação ambiental já adotada em algumas escolas brasileiras, que seria um mecanismo para a readequação gradual e permanente da escola a essas novas premissas.

Os princípios que regem esse processo são caracolianos, por acreditar na escola como uma espiral de possibilidades e descobertas e por apresentar uma proposta de aprendizagem circular, que não se fecha e permanece inacabada na incompletude de avançar e recuar; de ensinar e aprender. Uma escola sustentável considera que o território é o espaço que constrói as identidades, ou seja, um currículo cultural do sujeito, da comunidade escolar e também da sociedade brasileira. Para esta passagem da escola ao mundo, vários projetos de gestão serão orientados, principalmente na perspectiva do fortalecimento da Com-Vida.

Constituem referências das escolas sustentáveis as nossas três pedagogias:

- Cuidado - considera o sujeito historicamente situado, consciente de sua existência, seus sonhos, valores e sentimentos, porém entrelaçado no marco de um projeto coletivo da humanidade. É a Ética do Cuidado ${ }^{6}$ num contexto social mais amplo, que envolve cuidado com o nosso corpo, a família, a escola, o bairro, o município, o estado, a nação, o planeta, o universo...

- Integridade - capacidade de exercitar a visão complexa e vivenciar o sistema educativo desenvolvendo uma práxis coerente, entre o que se diz e o que se faz. Um espaço que proponha o enraizamento dos conceitos trabalhados na ação cotidiana.

a) Diálogo - exercício constante de respeitar as diversas referências, acadêmicas ou populares, os valores de cada biorregião, e

${ }^{6}$ Por Ética do Cuidado, termo cunhado por Leonardo Boff (Saber Cuidar: ética do humano, 1999), entende-se: "um consenso mínimo a partir do qual possamos nos amparar e elaborar uma atitude cuidadosa, protetora e amorosa para com a realidade... Esse afeto vibra diante da vida, protege, quer expandir a vida”. 
a capacidade de transformar a escola como um espaço republicano - a coisa pública, de todos e todas, de aprendizagem ao longo da vida - e de democracia.

Resumidamente, por meio de suas três pedagogias, as escolas sustentáveis querem envolver escola e comunidade em pequenos projetos ambientais escolares comunitários. Elas consideram o sujeito [estudante] percebido no mundo, suas relações no mosaico social da escola e seu entorno [comunidade] e no desenvolvimento de atividades, projetos e planos que se entrelacem com o local [bairro, município educador sustentável]; promovendo diálogos entre os conhecimentos científicos, culturais e saberes locais.

\section{$2 \mathrm{O}$ processo formativo}

Com o objetivo de criarmos sinergias para que a educação ambiental e as diversas dimensões da sustentabilidade entrem "na corrente sanguínea" da política de educação, propomos processos formativos para Escolas Sustentáveis. O substrato primordial desta proposta está nas parcerias estabelecidas em dois espaços de articulação:

i) orquestração de várias áreas do MEC: o Programa Mais Educação para o Ensino Médio, e a Coordenação-Geral de Educação Ambiental, no âmbito da Secretaria de Educação Continuada, Alfabetização e Diversidade (SECAD), com o Programa Ensino Médio Inovador, da Secretaria de Educação Básica (SEB); bem como da Rede de Educação para a Diversidade (SECAD/UAB/ CAPES) com as três universidades públicas federais (Universidade Federal de Ouro Preto, Universidade Federal do Mato Grosso, Universidade Federal do Mato Grosso do Sul) que aderiram à proposta de atuar em processos formativos voltados a escolas; e,

ii) participação direta, no cotidiano, de escolas do Ensino Médio, que se transformarão em polos de aprendizagem presencial e a distância, envolvendo 2.800 cursistas entre estudantes, professores e gestores. 
O processo formativo a distância do Projeto Escolas Sustentáveis tem 90 horas de duração, repartidas em três módulos, com início no segundo semestre de 2010, já com a promessa de ser ofertado e complementado por outras universidades.

Para propiciar a interação entre as escolas participantes, o processo formativo começa pela formação presencial (com duração de $40 \mathrm{~h})^{7}$ de professores e gestores públicos de educação. Este encontro possibilitará o aperto de mãos, o sorriso, que não é tão somente um sinal gráfico, e uma atmosfera de sinergias para a construção coletiva que carrega a oportunidade de uma rede de saberes para a formação contínua.

A formação de articuladores pedagógicos é essencial, já que serão eles os responsáveis para que a escola se mova e se envolva no curso a distância. Este processo acolhe a diversidade como pauta essencial e reconhece que somos diferentes, aceitando possíveis desacordos, e que nem sempre os consensos serão necessários. O que importa é a nossa capacidade de dialogar sob o nosso talento em mediar os conflitos por meio de uma proposta ecopedagógica.

Educação a Distância - por meio de materiais pedagógicos, ambiente moodle e diálogos virtuais constantes, as equipes do MEC e das três universidades estarão atentas para ajudar, orientar e colaborar na aprendizagem coletiva da construção de escolas sustentáveis.

O primeiro módulo da formação parte do EU [estudante] e meu engajamento. Tem por objetivo incitar a memória ambiental para a recuperação do engajamento individual no processo formativo, ou seja, de que maneira a dimensão educativa e ambiental toca a pessoa participante. Para tal, será trabalhado o registro da biografia ecológica de cada cursista a partir de sua pegada ecológica individual ${ }^{8}$.

Estamos propondo que esta jornada pedagógica se inicie com cada pessoa envolvida. Isto é, que cada participante do projeto pense em sua

${ }^{7}$ O encontro presencial aconteceu em agosto de 2010 no coração do Pantanal, graças a uma parceria com o SESC-Pantanal.

${ }^{8} \mathrm{O}$ conceito de pegada ecológica é amplo e cientificamente comprovado, envolvendo uma matemática que não se pretende abordar em detalhes na escola, mas sim os seus conceitos como parte avaliativa dos processos de reflexões pessoais e coletivas sobre o modo de vida: alimentação, energia, mobilidade, água, serviços e consumo. No sítio oficial, há opção de vários idiomas. [http://www.myfootprint.org/]. 
própria vida e perceba quando começou seu interesse pela dimensão ambiental. A anotação desta memória poderá ser feita em qualquer linguagem, desde que registrada em cartaz, fotografia, redação, carta, blog ou afins. Trata-se de uma biografia ecológica que espelhará a memória de nossa própria existência, no mergulhar de si mesmo à construção de uma ecoidentidade. Mas para além desta reflexão histórica, queremos abrir um convite para que os conceitos da pegada ecológica sejam internalizados e coletivizados no espaço da escola.

Para o segundo módulo, trazemos o OUTRO [escola] e a coresponsabilidade. Ele envolve uma pesquisa do perfil da escola em sua amplitude socioambiental, de planejamentos físicos e pedagógicos, considerando o espaço, o currículo e a gestão. E abre um diálogo interno, com a implementação da Com-Vida, para o dimensionamento dos impactos atuais e as potencialidades para a constituição de uma escola sustentável.

Caberá a cada Com-Vida adaptar tudo ao seu contexto particular, acomodando conceitos, mudando títulos, distribuindo tarefas ou revendo pontes para novas religações. Será preciso ponderar sobre quais projetos são possíveis e, sobremaneira, avaliar o que, por que ou aonde queremos chegar'.

Assim, após este mapa socioambiental individual, o convite é construir um mapa socioambiental da escola e seu entorno imediato, identificando detalhes arquitetônicos, problemas ambientais, e o perfil socioeconômico dos integrantes da escola. A identificação dos projetos, atividades e experiências prévias serão enriquecidas com um prognóstico de quais "tribos" existem no interior da escola, quais forças podem impulsionar o Projeto Escolas Sustentáveis e quais podem oferecer limites ao processo de aprendizagem para a sustentabilidade.

O terceiro módulo aproxima o MUNDO [comunidade] com a escola como referência de sustentabilidade. $O$ módulo objetiva fortalecer escola e comunidade para influírem nas políticas locais em favor da sustentabilidade socioambiental. Para tal, os grupos participantes farão

\footnotetext{
${ }^{9}$ Veja a publicação Formando Com-Vida / Construindo a Agenda 21 na Escola, que pode ajudar nesta fase e ser encontrada no endereço: http://portal.mec.gov.br/secad/CNIJMA/ arquivos/com_vida.pdf
} 
um projeto da escola sustentável [objetivos, metodologia e resultados esperados], considerando-a um espaço educador sustentável.

Se a alimentação e a segurança alimentar puderem ser repensadas, um bom convite para um cardápio mais natural encontra ressonâncias nas diversas propostas da permacultura, da agrofloresta e da saúde (LEGAN, 2007).

Uma reforma da escola pode ser criada com bons projetos da bioarquitetura, com inspiração nas belezas do Fritz [figura 2]. Um estudo sobre a biodiversidade da escola pode sugerir um teatro, um role play game [RPG] ou até a criação de diversos instrumentos musicais com sucata, sucesso garantido para aquela banda alternativa.

Campanhas e projetos para reduzir o consumo de energia constituem uma abordagem que não pode faltar nas escolas! Se o projeto for integrado, a professora de inglês poderá ajudar nas informações sobre a origem do projeto na Inglaterra ${ }^{10}(\mathrm{UK}, 2007)$. Enfim, diversas opções, projetos e atividades podem ser criados e recriados.

\section{A metáfora do artista}

É como utilizar a metáfora de Hundertwasser (2002), um austríaco genial que sempre aliava arte e ecologia no contexto arquitetônico ou da pintura. Para Fritz (assim ele gostava de ser chamado), cada pessoa tem o seu direito à janela, e por isso, elas nunca devem ser iguais. Subvertendo a ordem, o arquiteto propunha um jardim com bolor nas paredes e nos tetos da casa!

Fritz sugeria que cada ser humano fosse responsável por cinco peles, conceitos que podem ser incorporados pelo Projeto Escolas Sustentáveis.

A primeira pele é a nossa própria epiderme, o "direito à janela" de viver nossa própria química, no tecido epitelial que traz diferentes texturas, aromas, cores e sensações.

\footnotetext{
${ }^{10}$ No sítio do Projeto Escolas Sustentáveis é possível ter inúmeras referências, atividades e informações: http://www.sustainableschoolsproject.org/school.
} 
A segunda pele é o nosso vestuário, que indica as relações de comércio e possibilidades de talvez criar novas modas que sejam ecologicamente sustentáveis.

A terceira pele é a casa, que o genial arquiteto metaforiza sobre "o direito de janela e o dever de árvore”, isto é, ter o direito da janela, mas respeitar o espaço coletivo, reconhecendo o "dever da árvore" como uma ética que acolha os movimentos coletivos. Plantando nas paredes, propõe que o húmus não seja só da terra, mas também da estrutura arquitetônica, tornando as paredes esteticamente repintadas e replantadas!

A quarta pele é a sociedade, na formação da identidade, da cidadania e do culto das pequenas tradições, como moedas, bandeiras ou símbolos que podem ser recriados.

A quinta pele é a ecologia, trançada com as demais peles, fecundas na natureza, mas que solicita um envolvimento político, tanto na ação individual [direito da janela] cotidiana quanto em movimentos organizados [dever da árvore].

\section{A trans-formação}

Como uma jornada para o sabor da invenção pedagógica, temos especial interesse no processo de construção e de trans-formação, para além dos produtos finalizados.

O mais importante, entretanto, é que a proposta não seja isolada de um contexto curricular. Se o currículo for realmente fenomenológico (PASSOS; SATO, 2002), ele terá que ser criado à luz da existência dos envolvidos na escola, no âmago da biografia ecológica que se complementa nas cartografias dos desejos de mudanças.

É possível que a escola não seja a resposta de problemas, mas ela reproduz os discursos da sociedade. Os espaços educadores sustentáveis desejam que a escola transcenda isso, sendo geradora de uma cultura prósustentabilidade. Esta postura, fomentada por um currículo apropriado, permite que as preocupações socioambientais, no âmbito global, sejam absorvidas pela consciência individual.

Assim, conseguiremos uma transformação - e por que não falar em trans-valoração - para alterar o ideário desenvolvimentista e consumista para práticas sustentáveis e duradouras. E para além de nossas reflexões 
escolares, um currículo da vida, a mudança de valores que consiga nos tornar pessoas melhores, capazes de enxergar as injustiças do mundo e lutar para que o planeta seja de todos e todas!

\section{REFERÊNCIAS}

HUNDERTWASSER, Friedensreich. KunstHausWien. Wien: Taschen, 2002.

, Complete graphic work: 1951 - 1976. Vienna: Prestel, 2008.

LEGAN, Lúcia. A escola sustentável. Eco-alfabetização pelo ambiente. São Paulo: Imprensa Oficial \& Pirenópolis: IPEC, 2007.

PASSOS, Luiz Augusto; SATO, Michèle. Educação Ambiental: o currículo nas sendas da fenomenologia Merleau-pontyana. In: SAUVÉ, Lucie; ORELLANA, Isabel et SATO, Michèle (Dir.) Sujets choisis en éducation relative à l'environnement - D'une Amérique à l'autre. Montréal: ERE-UQAM, 2002, Tome I: p. 129-135.

SENRA, Ronaldo; SATO, Michèle; OLIVEIRA, Herman. Projetos Ambientais Escolares Comunitários, caderno3. Brasília: Coordenação Geral de Educação Ambiental, MEC, 2009.

UNITED KINGDON, House of Commons. Sustainable schools: are we building schools for the future? London: Education and Skills Committee, House of Commons, 2007. 